\title{
REVIEW OF 560 CASES OF YAG LASER CAPSULOTOMY
}

\author{
Zafar Dawood, Sajid Ali Mirza and Abdul Qadeer
}

\begin{abstract}
OBJECTIVE: To review the pattern of different types of posterior capsular opacification and relative frequency of complications after YAG laser capsulotomy.

DESIGN: Descriptive case series.

SETTING: Ziauddin Medical University and Dr. Akil Bin Abdul Kadir Welfare Eye Hospital, Karachi from May 2002 to June 2004.

PATIENTS AND METHODS: Five hundred and sixty patients were treated for capsular opacification with Neodymium YAG (Nd: YAG) laser during study period. All procedures were done on Ziess Visual YAG II Plus.

RESULTS: After capsulotomy, the visual acuity improved in 526 patients (93.92\%) and no improvement was seen in $34(6.08 \%)$ patients. Out of 560 patients, 314(56.07\%) patients presented with Elschnig Pearls, 237(42.33\%) had capsular fibrosis and 9(1.60\%) had capsular wrinkling. The main complications were temporary increase in intraocular pressure ( $5 \mathrm{~mm} \mathrm{Hg}$ or more) and mild anterior uveitis. However, these complications were found to be transient in nature, with most of these patients settling down during first week of their treatment. Four patients developed retinal detachment, eight showed long term elevation of intraocular pressure and 2 developed cystoid macular edema.

CONCLUSION: Nd: YAG laser is an effective and safe method for the management of posterior capsular opacification.
\end{abstract}

KEY WORDS: Capsular opacification. Capsulotomy. Management. Complications.

\section{INTRODUCTION}

Opacification develops in the posterior capsule within 2-3 years of extracapsular cataract surgery in at least $25 \%$ to $50 \%$ of eyes. ${ }^{1}$ Posterior capsular opacification (PCO) varies from proliferation of Elschnig pearls to capsular wrinkling and folding of posterior capsule without actual opacification, formation of fibrous membrane and less commonly an inflammatory membrane which develops in weeks associated with iritis. Before the Neodymium-Yttriun-Aluminium-Garnet (Nd: YAG) laser came into use, this condition was treated by performing a small capsulotomy with a needle knife or 27gauge needle either at the time of original operation or as a secondary procedure. In the last two decades, Nd: YAG laser has gained popularity as a noninvasive method for treating posterior capsule. Aim of treatment is to create an opening in the posterior capsule. Common indications for YAG laser capsulotomy include diminished visual acuity, diplopia, glare and inadequate fundus view. ${ }^{2}$ YAG laser capsulotomy is a simple and relatively safe procedure. There are no restrictions of activities after the procedure. The majority of patients enjoys improved vision almost immediately. The rest of patients experience gradual improvement over the next several days. However, the $\mathrm{Nd}$ : YAG laser capsulotomy procedure has been associated with some complications such as damage to
IOL, post laser intraocular pressure increase, cystoid macular edema and increased incidence of retinal detachment. Common types of posterior capsular opacification are Elschnigs pearls which is caused by proliferation and migration of residual equatorial cells along posterior capsule and capsular fibrosis which is due to fibrous metaplasia of epithelial cells. Elschnigs pearls is the most frequently seen type of PCO. It is more common in children. ${ }^{2}$

\section{PATIENTS AND METHODS}

Five hundred and sixty patients having various forms of posterior capsular opacification were treated with YAG laser capsulotomy. Out of 560 patients, 301 were male and 259 were females. Age of the patients varied from 19 to 81 years. In 135 cases, extracapsular cataract extraction and phacoemulsification had been done in our hospital. It also included those cases, which were referred from other ophthalmic centers in the city where YAG laser facilities were not available. The study period extended from May 2002 to June 2004 . Visual acuity ranged from $3 / 60$ to $6 / 12$. The presenting complaint in most of these patients was postoperative reduction of vision. In eleven cases of proliferative diabetic retinopathy, which were sent to us for Pan Retinal Photocoagulation (PRP), YAG laser capsulotomy was done because of poor visualization of fundus. 


\section{METHOD OF TREATMENT}

Each patient gave informed consent prior to laser therapy. The pre-operative best corrected visual acuity, intraocular pressure and anterior and posterior segment abnormalities were recorded. In case of dense posterior capsular opacification B-scan ultrasonography was done to exclude posterior segment pathology. The patients were seated on slit lamp with head properly fixed. Most of the cases were done without the use of contact lens. In some cases, Abraham capsulotomy contact lens was used with topical anaesthesia. Contact lens helps to focus the laser beam on to the posterior capsule. It also controls eye movement and separate the eyelid. Pupil dilatation was done in most cases. Position of the pupil was noted prior to dilatation especially if pupil was eccentric. All procedures were done on Ziess Visual YAG II plus which has super gaussian mode. Wavelength of therapy beam was 1064 . The radiation was produced by a Qswitched mode. It causes optical breakdown or photo disruption which produces an incisional effect. There were 10 energy levels. The lowest level corresponded to $0.3 \mathrm{mj}$, the highest to approximately $10 \mathrm{mj}$. It provides a 4 spot aiming beam system. The 4 spots then merged to form a single spot. In astigmatism because of distorted aiming beam fusion of 4 spots was not possible, therapy beam was also distorted and a higher energy level was required to achieve desired effect. The size of capsulotomy was depending upon nature of indication of capsulotomy. Mostly capsulotomy was done for visual reasons and size was in the range of 3-4 $\mathrm{mm}$. Larger opening was required in cases where vitreoretinal intervention or panretinal photocoagulation for diabetic retinopathy was required. Once the procedure was completed, one drop of Dexamethasone and one drop of Levabenalol was instilled. When higher energy was used, one tablet Diamox $250 \mathrm{mg}$ stat was also given. In all patients intraocular pressure was monitored at one hour time and later on they were discharged on Dexamethasone eye drop $0.1 \%$ four times a day and Levabenalol eye drop twice a day. Patients were scheduled to visit after one day, one week and one month subsequently. Only those patients followed up for a minimum of six months period were included in this study.

\section{RESULTS}

YAG laser capsulotomy was well tolerated by patients. The mean follow up period after capsulotomy was 12 months (Range from 6 to 18 months). Five hundred and thirty two (95.0\%) of these eyes were pseudophakic with posterior chamber implant and 12 eyes
(2.15\%) with anterior chamber implant. Sixteen eyes $(2.85 \%)$ were aphakic. In all eyes capsulotomy was successfully performed in single session. The energy level required for adequate capsulotomy ranged from $0.9 \mathrm{mj}$ to $4.5 \mathrm{mj}$. Mostly the energy level required was below $2.0 \mathrm{mj}$ (Table I). Total energy required in order to achieve a satisfactory capsulotomy was ranged from $8 \mathrm{mj}$ to $320 \mathrm{mj}$. In this series, Elschnig pearls (314 patients) was the most common type of posterior capsular opacification followed by capsular fibrosis in 237 patients (Table II). The interval between cataract extraction and capsulotomy ranged from 4 to 60 months. Presenting visual acuity ranged from $3 / 60$ to $6 / 12$. In 34 eyes, no improvement was seen after Yag laser capsulotomy. Macular pathology was the cause of non-improvement in most of the patients. The remaining 387 patients showed 3 to 6 lines improvement and 139 patients showed 1 to 2 lines improvement (Table III). Fourteen patients developed mild anterior uveitis. With topical steroid/NSAID, this settled down in majority of cases during first week. Intraocular pressure was high in 116 cases after the procedure in the range of $20-30 \mathrm{~mm} \mathrm{Hg}$ (Rise of $5 \mathrm{~mm} \mathrm{Hg}$ or more). Antiglaucoma medication was given to these patients. Except 8 patients, all cases had their intraocular pressure settled down within normal limit in a week. Four patients who showed long term raised intraocular pressure were already diagnosed as primary open angle glaucoma. Four patients developed retinal detachment, two of them were high myopic. In 3 patients, minor pitting of IOL occurred that did not cause any visual impairment. Two patients developed cystoid macular edema. One was diagnosed clinically and other on FFA examination (Table IV).

TABLE I:

ND: YAG LASER ENERGY APPLIED

\begin{tabular}{|l|l|}
\hline \multicolumn{1}{|c|}{ Energy } & \multicolumn{1}{c|}{ No. of Patients } \\
\hline $1-1.5 \mathrm{mj}$ & $273(48.76 \%)$ \\
\hline $1.5-2 \mathrm{mj}$ & $241(43.02 \%)$ \\
\hline $2-4.5 \mathrm{mj}$ & $46(8.22 \%)$ \\
\hline Total & $\mathbf{5 6 0 ( 1 0 0 \% )}$ \\
\hline
\end{tabular}

TABLE II:

TYPE OF POSTERIOR CAPSULAR OPACITY

\begin{tabular}{|l|ll|}
\hline Elschnig's Pearls & 314 & $(56.07 \%)$ \\
\hline Capsular Fibrosis & 237 & $(42.33 \%)$ \\
\hline Capsular Wrinkling & 9 & $(1.60 \%)$ \\
\hline
\end{tabular}




TABLE III:
POST - YAG LASER CAPSULOTOMY
IMPROVEMENT IN VISION
\begin{tabular}{|l|ll|}
\hline \multicolumn{2}{|c|}{ Visual Improvement } & \multicolumn{2}{c|}{ No. of Eyes } \\
\hline No Improvement & $34 \quad(6.07 \%)$ \\
\hline 1-3 Lines & $387(69.11 \%)$ \\
\hline 4- 6 Lines & $139 \quad(24.82 \%)$ \\
\hline
\end{tabular}

TABLE IV:

ND: YAG LASER COMPLICATIONS

\begin{tabular}{|l|c|}
\hline \multicolumn{1}{|c|}{ Complication } & No. of Patients \\
\hline Long term raised IOP & 8 \\
\hline Damage to the IOL (pitting) & 3 \\
\hline Retinal Detachment & 4 \\
\hline Mild anterior uveitis & 14 \\
\hline Cystoid macular edema & 2 \\
\hline \multicolumn{1}{|c|}{ Total } & $\mathbf{3 1}$ \\
\hline
\end{tabular}

\section{DISCUSSION}

Posterior capsular opacification is the most common late complication of uncomplicated extra capsular cataract surgery. Elschnig pearls is the most common type of PCO in this study followed by capsular fibrosis. This is similar to the data of the study done by Firdous $\mathrm{M}$ et al. $^{3}$ The cause of posterior capsular opacification following cataract extraction is multifactorial. It depends on IOL optic material, IOL design, surgical technique etc. Certain material and design like acrylic material in contrast to Poly -methyl methacrylate (PMMA) and silicone lenses and a square edge optic appears to inhibit PCO. The capsular bending ring significantly reduces anterior capsular fibrosis and shrinkage as well as posterior capsular opacification. The ring may be useful in patients who are at high risk of developing eye complications from capsular opacification that require YAG Laser capsulotomy. ${ }^{4}$ Implanting a lens with complete anterior capsule overlap on the IOL also reduce posterior capsular opacification. ${ }^{5}$ Posterior capsular opacification is a significant problem in almost all pediatric patients unless the posterior capsule and anterior vitreous are removed at the time of surgery. ${ }^{6}$ In very young patients special type of $\mathrm{Nd}$ : YAG laser can be used, which allows for 90 degree rotation of the laser delivery system to treat recumbent pa- tients who may be under general anaesthesia. In general minimum shots and energy should be used. In cases where the thickening is due to Elschnig pearls, a minimum energy setting of less than $1 \mathrm{mj}$ and usually less than 10 shots are necessary for an adequate opening. On the other hand, if there is a thickened fibrotic posterior capsule, a greater power of $3 \mathrm{mj}$ or more and as many as 50 to 100 shots may be necessary for adequate opening. An average size of capsular opening is $3-4 \mathrm{~mm}$. There is merit in making a smaller opening as this tend to result in less vitreous disturbance. One of the main complication after $\mathrm{Nd}$ : YAG laser capsulotomy is temporary elevation of intraocular pressure and this occurs one to three hours after treatment. There was no correlation between intraocular pressure elevation and number of laser shots applied or amount of laser energy delivered in our clinical observation. Elevation of intraocular pressure may be caused by many other factors like amount of lens cortex liberation, condition of already compromised angle, presence or absence of IOL, injury to liquefied vitreous (myopia and vitreoretinal disease), vitreous prolapse in anterior chamber and large capsular opening. Long-term elevation of intraocular pressure above the precapsulotomy baseline is often present in glaucoma patients and in those who experience a significant intraocular pressure increases within hours after the capsulotomy. ${ }^{7}$ In this study, incidence of long term elevation of intraocular pressure was $1.43 \%$ (8 patients), retinal detachment was $0.72 \%$ (4 patients) and cystoid macular edema was $0.36 \%$ (2 patients). Similar incidence of complications after YAG laser capsulotomy has also been reported in studies done by Steinert RF et al , ${ }^{8}$ Iqbal $\mathrm{Z}$ et al ${ }^{9}$ and Hussain MM et al. ${ }^{10}$ Incidence of cystoid macular edema was low in this study as compared to the result published in other studies. This may be due to the fact that we performed YAG laser capsulotomy mostly after 6 months of cataract extraction. Problems related to poor focusing include pits of the optics, rupture of anterior hyaloid face, corneal damage ${ }^{11}$ and iris bleeding. Factors that determine the extent of pitting or damage to IOL depend on inherent resistance of a particular IOL damage by laser, amount of energy used in the procedure and focusing accuracy of the surgeon. One method to prevent IOL damage is to perform a racquet shaped posterior capsulotomy ${ }^{12}$ which leaves the central optical zone of IOL undam- 
aged even after few minor pittings. Other possible complications are mild anterior uveitis, posterior IOL subluxation or dislocation, chronic endophthalmitis. Retinal complications including retinal tear, macular hole, ${ }^{13}$ cystoid macular edema and retinal detachment are result of opening in the capsule and are not the specific complications of YAG Laser. ${ }^{14}$ Retinal detachment is a serious complication. It occurs more frequently in eyes with thickened capsules without an implant in which vitreous tends to move forward. One of the theoretical mechanism for retinal detachment is liquefaction and anterior displacement of anterior vitreous face causing posterior vitreous detachment and retinal tear formation in predisposing eyes. Because of high risk of retinal complications in some patients, YAG laser capsulotomy should be avoided until the patient's impairment of vision caused by capsular opacification warrant the increased risk of retinal complications associated with performance of capsulotomy. ${ }^{15}$ It has been suggested that longer the interval between cataract surgery and capsulotomy, the smaller the risk of retinal complication. ${ }^{16}$ Retinal detachment and cystoid macular edema may develop many months after capsulotomy therefore patients undergoing YAG laser capsulotomy require long term follow up to detect and treat these serious complications.

\section{CONCLUSION}

The Nd: YAG laser capsulotomy is a safe and effective method to treat posterior capsular opacification. It is a non-invasive procedure and avoids all the complications of surgical capsulotomy and associated with local block. YAG laser capsulotomy carries a low but definite risk of some serious complications. Regular follow up of all these patients is necessary to avoid complications like glaucoma, retinal detachment and cystoid macular edema. One should wait for 6 months after cataract surgery before doing YAG laser capsulotomy. Minimum energy combined with minimum number of precisely focused shots is necessary to achieve desired effect.

\section{REFERENCES}

1. Spalton DJ. Posterior capsular opacification after cataract surgery. Eye. 1999; (13): 489-92.

2. Kanski JJ. Clinical Ophthalmology, A systemic approach. $5^{\text {th }}$ Edition. Butterworth Heinemann. London 2003: p.180.

3. Firdous M. Posterior capsular opacification following cataract surgery. J Coll Physicians Surg Pak. 2001; 11(6): 352-4.

4. Nishi O, Nishi K, Menapace R, Akara J. Capsular bending ring to prevent posterior capsular opacification. J Cataract Refract Surg. 2001; 27 (9): 1359-65.

5. Smith SR, Daynes T, Hinckley M, Wallin TR, Blosan JR. The effect of lens edge design versus anterior capsule overlap on posterior capsular opacification. Am J Ophthalmol. 2004; 138(4): 521-525.

6. Atkinson CS, Hiles DA. The Nd: YAG laser in pediatric population. Am J Ophthalmol. 1994; 118:496-501.

7. Ge J, Wand M, Chiang R, Paranhos A, Sheild M B. Long term effect of $\mathrm{Nd}$ : YAG laser posterior capsulotomy on intraocular pressure. Arch Ophthalmol. 2000; 118:1334-7.

8. Steinert RF, Puliafito CA, Kumar SR, Dudak SD, Patel S. Cystoid macular edema, retinal detachment and glaucoma after Nd: YAG laser posterior capsulotomy. Am J Ophthalmol.1991;112(4):37380.

9. Iqbal Z, Palimar P. Risk factors for early posterior capsular opacification and morbidity following $\mathrm{Nd}$ : YAG laser capsulotomy. Pak J Ophthalmol. 2002; 18(4): 98-101.

10. Hussain MM. Complications after Nd; YAG laser capsulotomy. Pak J Ophthalmol.1996;12(1):13-15.

11. Panazai MN, Shawani MA, Hameed K. Posterior capsular opacification and Nd: YAG laser capsulotomy in Helpers Eye Hospital, Quetta. Pak J Ophtalmol. 2004; 20 (3):115-118.

12. Shaikh ZA. Racquet shaped posterior capsulotomy using Nd: YAG laser. Pak J Ophthalmol. 1999; 15(1): 10-14.

13. Chaudhary R, Sheidow T, Gonder JR, Merchea MM. Macular hole following YAG capsulotomy. $\mathrm{Br}$ J Ophthalmol. 1999; 83:753.

14. Winslow RL, Taylor BC. Retinal complications following YAG laser capsulotomy. Ophthalmology. 1985; 92(6): 785-9. 
15. Javitt JC, Trelsch JM, Canner JK, Kolb MM, Sommer A, Steinberg E. National outcome of cataract extraction increased risk of retinal complications associated with Nd: YAG Laser capsulotomy. The cataract patient outcome research team. Ophthal- mology. 1992; 99:1487-97.

16. Bukelman A, Abrahami S, Oliver M, Pollack A. Cystoid macular oedema following Nd: YAG laser capsulotomy. A prospective study. Eye. 1992; 6:35-38.

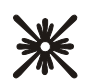

AUTHOR AFFILIATION:

Dr. Zafar Dawood (Corresponding Author)

Assistant Professor

Department of Ophthalmology

Ziauddin Medical University

Karachi, Sindh - Pakistan.

Email: zafar_dawood@hotmail.com

Dr. Sajid Ali Mirza

Associate Professor

Department of Ophthalmology

Ziauddin Medical University

Karachi, Sindh - Pakistan.

Dr. Abdul Qadeer

Ophthalmologist

Dr. Akil Bin A. Kadir Eye Hospital

Karachi, Sindh - Pakistan. 